\title{
The Status of the Propaganda Theorist: A Rejoinder
}

\author{
STANLEY B. CUNNINGHAM University of Windsor
}

Key Words: Propaganda; propaganda theorist; communication; belief; truth; Ellul.

\begin{abstract}
In Propaganda Talk (1988), Dennis Rohatyn's fictional spokesperson argues that even those (including Jacques Ellul) who analyze and discuss propaganda are themselves propagandists. This 'membership claim' seriously misrepresents the agency of the propaganda theorist. Different aims and epistemic values distinguish the actions of the theorist from those of the propagandist. Frontline propagandists prefer to use truth, but only because of its strategic utility. Most of all they value belief and credibility; and their principal aim is to modify behavior. Propaganda theorists, by contrast, esteem truthfulness (or "knowing well"); and their principal aim is to understand and to disclose propaganda as a social phenomenon.
\end{abstract}

In the dialogue Propaganda Talk (1988), Dennis Rohatyn, through the mouthpiece of his fictional theorist, Dr. Uve Binad, makes the claim that the propaganda analyst or theoretician - that is, anyone who talks about or studies propaganda - is also and necessarily, a practitioner of propaganda, and that it is naive to suppose otherwise.

But there's no way to climb out of the propaganda net, so you might as well relax and have a good roll.

$Q$ : Does that entail that this conversation is also propaganda?

You said it. Even "educational" discussions of propaganda exemplify the category they classify. That's OK provided you don't im- agine you're in another category. That's just naive. We are all agents, not spectators, in the drama of existence. Today that includes bureaucratic rhetoric, academic jargon, and everything else we perform on the world stage.

Q: But if you too are a propagandist, not a theorist who eschews propaganda, what is your object or goal?

To warn those who flatly deplore propaganda to examine themselves before they criticize others (p. 90).

These core statements about the status of the propaganda discussant form part of the description of propaganda as a "selfreferential artifact" (p. 89) Dr. Binad, that is, views himself not as a neutral, detached theoretician (which is made to seem impossible), but rather as someone who, in both analyzing and deploring propaganda, is ipso facto a propagandist. At the same time, there can be no doubt that Propaganda Talk is also theoretical. It is one of the "educational discussions" referred to; and it is embedded within an academic anthology dedicated to the interplay of logic and communication.

To avoid circumlocution let us call Binad's position the 'membership claim', and take that to mean that the propaganda theorist or analyst is also and ineluctably a propagandist.

There is no serious attempt to restrict the scope of this thesis. Even when Binad re- 
marks that the propaganda that mesmerizes elites or that backfires on the propagandist him/herself should be called "metapropaganda" (p. 85), that amounts to little more than enlarging the concept of propaganda by adding a prefix. Furthermore, should there be any doubts about the intended scope and self-referential nature of Binad's membership claim, the remarks offered in the immediately preceding pages do much to escalate the thesis:

Q: It's too bad you can't avail yourself of the comforts propaganda provides.

Don't be sarcastic. Propaganda enslaves everyone, but most of all those who imagine themselves free from it. This is why I admire Jacques Ellul....Ellul is also the only author I've ever encountered who doesn't exempt himself from the charge of spreading propaganda. He knows that what he is doing to expose and diagnose is propaganda, too, and that this paradox is unavoidable....[O]nly Ellul has the guts to admit that every attack on propaganda is itself propaganda, including his own.

Q: But if everything we communicate is propaganda, how do we ever distinguish (in principle) between propaganda and nonpropaganda?

\section{I don't think we can (pp. 88-89).}

The propositional core of Binad's claim, then, would read something like this: "everything we communicate about propaganda, including this statement (dialogue) is itself propaganda." Even this, however, may not do justice to the comprehensiveness of Binad's claim because a primary concern in his relevant comments, we have seen, is the status of the propagandist and the nature of his/her actions. A good deal of his case hinges on his own self-image and upon the alleged propagandistic status of premier theorist, Jacques Ellul. Binad's dialogue and Ellul's theorizing supposedly confirm the assertion that propaganda is a self-referential artifact.

Binad's membership claim, however, assumes self-destructive proportions. First, "everything we communicate is propaganda" and "propaganda enslaves everyone" (including, of course, the propaganda theorist) are extrapolations which carry Binad's thesis well beyond the membership claim proper. That claim has now been transformed into a tautology: All communication is propaganda since Binad agrees that there is nothing "in principle" to distinguish between propaganda on the one hand, and non-propaganda communication on the other. Second, by virtue of propaganda's power to obfuscate, and its power to weaken both our ability and disposition to distinguish between truth, illusions and falsehoods (pp. 78-79, 81), the extrapolated claim is unwieldy, if not ultimately incoherent.

Why, then, should we even bother listening to Dr. Binad at all since he can only add to the confusion? Even as we allow that propaganda sometimes (or often) uses truths selectively, it is still hard to see how the membership claim, as extrapolated, is instructive since Binad does not think there is anything "in principle" to distinguish between propaganda and genuinely informative communication. Ultimately it is this impasse in the dialectic that leads Binad to take refuge in ineffability:

\section{Q: But if propaganda is everywhere, then it's nowhere. You can't detect or describe} it.

It's ineffable, just like the Holy Spirit, or more accurately, the Demonic Spirit (p. 89).

Pushed further, Binad voices the futility of "deriving rational solutions to figure out an irrational universe", and ends up, where this paper began, by characterizing propaganda as a "self-referential artifact."

Given this regression into ineffability and impotent rationality, is there sufficient coherence to warrant our attention? While the extrapolations ostensibly serve to underscore Binad's point that every level of propaganda talk is inescapably 
propagandistic, they ultimately sabotage this central tenet. Accordingly, the only charitable step available now is to ignore the excesses of the membership-claim extrapolations, and to return to the more restricted universality of the membership claim proper: every propaganda theorist (discussant, analyst) is a propagandist (or, more abstractly, every discussion about propaganda is itself an instance of propaganda).

In this more constrained form as a thesis about the status of the analyst/ discussant, the point raised by Binad does warrant our attention because it comes at a time of renewed interest in propaganda studies (Jowett, 1987; Silverstein, 1987). Indeed, one of the nettlesome issues in propaganda scholarship has always been the degree of ambiguity in the concept of propaganda. This latitude, in large part, is occasioned by differing conceptions of propaganda and its essential properties. Consider the role of falsity and intent. While conventionally associated with a family of falsity-types (lying, distortion, disinformation, deception, illusion, myth, stereotypes, half-truths, exaggerations, omissions), most contemporary theorists agree that propaganda relies primarily upon truths and facts (see below, p. 11). Binad himself concedes this: "And facts are much better than lies, not because they're facts but because they lend themselves to propaganda" (pp. 79-80). At the same time, there is a division between those who insist that deliberate intent to persuade is a necessary condition (Jowett \& O'Donnell, 1992, p. 212; Eaman, 1987, pp. 22-23), and those who argue that it may be of only minimal importance (Combs \& Nimmo, pp. 16-17), or not even a necessary condition at all (Ellul, 1973, p. 63, no. 4). Confusion over the concept of propaganda is reflected just as much in the very proliferation of its definitions (Johannesen, 1990, pp. 122-123). More recently, Leonard W. Doob, an established propaganda researcher, submits that "a clear-cut definition of propaganda is neither possible nor desirable" $(1989, \mathrm{p}$. 375). Not surprisingly, then, responses to the phenomenon of mass persuasion, including theoretical approaches, have varied widely (Sproule, 1988); and so, even as propaganda scholarship is greatly expanding, a great deal of uncertainty about this concept remains (Darnovsky et al., 1989). Selucky (1982) carries this one step further when she concludes that propaganda, as a heuristic device, is much less useful than, and secondary to, the concept of ideology.

Because it reflects this contemporary uncertainty about propaganda's boundaries, Binad's membership claim - without the extrapolations - can be viewed as an invitation to resolve some of this confusion about what propaganda is and is not, if only by attending a little more closely to the status and function of the propaganda theorist.

One of the highly questionable elements in Binad's case is exegetical. Binad asserts that the dean of propaganda theorists, Jacques Ellul, is really a propagandist and that he recognizes himself to be such. This reading of Ellul is germane since it appears to have reinforced Binad's commitment to the membership claim (p. 89). It is not at all evident, however, that Ellul ever implicates himself in this sort of paradox. In Binad's membership claim and its defense, there are four principal agents referred to: (i) the propagandist; (ii) the counterpropagandist; (iii) elites and intellectuals; (iv) the propaganda theorist/ discussant. According to Binad, the first, second and fourth ultimately become the same sort of agents. In Ellul, only the first two belong to the same class. Second, at the very least, Binad's contention is inconsistent with the spirit of those passages in which Ellul $(1957 ; 1973$, pp. 257,277 ) itemizes the qualities (e.g. perspicacity, vast learning and industry), and the kinds of approaches which are necessary conditions for the detection and understanding of propaganda. Third, 
even in that passage in which Ellul supplies his most explicit discussion of suitable and unsuitable methods for the study of propaganda (1973, pp. 264-277), there is nothing remotely corresponding to Binad's membership claim.

On the contrary, what Ellul says about propaganda and those it victimizes illustrates a very different kind of focus than Binad's. First, the genuine counter-informant, in an effort to neutralize propaganda and to register effectively his/her own information, is inevitably compelled to adopt the self-same strategies and techniques of the propagandist $(1957$, p. 67$)$. On the macro level, this is no less true of democratic political systems even though, if they remain true to such ideals as respect for individuals, the propaganda which they communicate will be ineffective and mediocre (1973, pp. 235-242). In passages such as these which spell out the way in which propaganda implicates those who are initially innocent and well motivated, there is nothing to indicate that Ellul conflates the role of the theorist (such as himself) with that of either the propagandist or counterpropagandist.

Second, Ellul argues that it is virtually impossible for the average person to distinguish between genuine information and propaganda. This is not a question of conceptual identity between information and propaganda as some have erroneously assumed Ellul to be saying (Steinfatt, 1979), but rather one of ineliminable confusion and practical limitations in the real order. One reason for this is that the sophisticated propagandist relies upon selective truths as much as possible. Another is that the average citizen has neither sufficient time nor opportunity for this kind of enterprise. Only the rare individual is empowered to disentangle the two forms of discourse:

But all this is propaganda, and only propaganda can provide it. Of course a superior man [sic], a man of tremendous culture and intelligence who has a constant supply of energy, can seek his own answers, can ac- cept absurdities, and can decide for himself what action to take. But we are not speaking of the superior man...but of the average man (1957, p. 76).

Given the virtual indistinguishability of truth from propaganda for most people on most topics, Ellul (1980) also encourages a policy of moral non-compliance, what he calls the "ethics of non-power", as one of our few forms of viable resistance.'

Third, in some discomfiting passages, Ellul portrays intellectuals and elitists as especially susceptible to the blandishments of propaganda. Because they delude themselves that they are immune to propaganda, intellectuals lower their guard and thereby render themselves most vulnerable of all (1973, pp.76, 111, 201). In all this there is nothing to suggest that propagandists belong to the class of elites and intellectuals. The former are manipulators and predators; the latter, at least initially, are unsuspecting victims.

When he speaks about propaganda, Ellul focuses on the propaganda process, upon message senders and receivers, not upon the propaganda theorist as such. "To study propaganda", he writes (1973, p. xii), "we must turn...to the propagandist; we must examine...a whole nation subjected to real and effective propaganda." In sum, it simply exceeds the textual evidence to suggest that Ellul takes the next step and smuggles the theorist or investigator into his net of propagandists. On the contrary, that would belie the critical perspective and concerns that motivate Ellul's own studies of mass communication (Christians \& Real, 1979). It would also have the effect of forcing Ellul, an apparent moralist, to include himself among the ranks of amoral practitioners (which is how he sees propagandists) a contradiction that is as difficult to believe as it would be offensive to Ellul himself (Ellul, 1981). ${ }^{2}$

Conceivably Binad's confusion might originate at those manifold points where Ellul deplores propaganda and makes it clear that he thinks that it is a monstrous 
and dehumanizing construct in technological society. But Ellul's evaluative stance and sometimes emotional language does not thereby transform him into a propagandist any more than the ACLU's spirited defense of the free-speech rights of American neo-Nazis makes it a Nazi sympathizer or propagandist. On the contrary, Ellul's role as commentator on propaganda, as a ubiquitous phenomenon, is categorically distinct from the status of the counterpropagandist. Typically, a theorist such as Ellul undertakes to say true things about propaganda. By contrast, the counterpropagandist uses and engages in propaganda techniques in response to a particular propaganda form, discourse or campaign. Binad's earlier insistence that we are "all agents, not spectators" (p.90), and that we belong in the same category simply belies distinguishable levels of intent and action-types within the notion of communicative agency.

It is possible, of course, that the (counter)propagandist and the theorist might also share certain properties (e.g., a professional desire to understand how propaganda works). The fact is, however, that Binad's membership claim seems to arise because it ignores some basic teleological imperatives that distinguish the agency of the propagandist from that of the theorist qua theorist. For one thing, while the principal aim of the theorist is solidly epistemic (see below, pp. 12-14), the ultimate intent of the propagandist is not simply to induce certain belief, but to secure a certain kind of behavior - unquestioning conformity in the actions of the intended audience. Ellul (1973, 25-32) calls this "orthopraxy". At the same time, propaganda works to eliminate critical judgment altogether (1973, 169-70, 173), "Propaganda," writes Ellul (1973, p. 180), "seeks to induce action, adherence, and participation - with as little thought as possible."

Within these divergent teleologies the propagandist and the theorist operate with very different attitudes towards the value of truth and its treatment. Truth, by which we customarily mean a conformity between both beliefs, judgments and reports on the one hand and that which is the case on the other hand, has always, until recently, been cherished as the supreme value of the human intellect. ${ }^{3}$ By extension it is characteristically presumed in normal discourse to be both a constraint and the intended goal of our reports and descriptions. In a word, truth is understood to be one of the principal ends of human discourse. The propagandist's attitude towards truth is inherently equivocal. As remarked above, the propagandist will use truth(s) or falsity (disinformation, illusion, distortions) depending upon which is most likely to work, but he/she prefers to work with truth. The motive is quite simple: for the propagandist, the supreme epistemic value is credibility because of its proven utility and effectiveness in persuading audiences. Better still, the propagandist wants to bring about the state of actually induced belief. Truth, even as a utility, is of secondary importance. To be sure, it enhances the credibility of both the propagandist and the message, whereas falsity, if unmasked, threatens both. Even so, there is no special appreciation of or commitment to truth for its own sake. Rather, it is what listeners and readers believe that moves them to act, not only true belief or that which they know to be the case. This is the fundamental operative premise in persuasion organizations (Altheide and Johnson, 1980; Bogart, 1976, pp. 128-141). Daniel Lerner (1980), in the context of discussing the "the strategy of truth", recounts an incident in World War II which illustrates this point:

As the touchstone of credibility became axiomatic in allied propaganda technique, some true stories were not told because they would not be believed. For example, photographs of German prisoners eating oranges in allied POW camps were eliminated from propaganda leaflets on the ground that disbelief among German soldiers (who had not seen an orange in years) 
would compromise the credibility of the leaflets as a whole (p. 387).

In unearthing the operative premises in the United States Information Agency during the Cold War, Leo Bogart records the same preference for credibility over truth:

\begin{abstract}
The "truth" may be misleading. A foreign policy position that really makes sense may be harder to propagandize than a dishonest or unsound one. It is apt to be more complex, hence less plausible....Films or books that are "overly realistic" about American life, such as [James Jones'] From Here to Eternity, maybe alright for an American audience but unsuitable overseas. Presenting a problem may (a) eclipse the solution and (b) serve the ends of Soviet Propaganda (p. 132).
\end{abstract}

Truth for the propagandist is reduced to the status of what is merely expedient or useful: it is a means only, something merely instrumental. That too is the most that can be said for truthfulness and honesty by which we mean the moral disposition to respect truth and its procedural safeguards in our utterances. Ellul points out that while propaganda uses facts as convenient tools, the process is inherently an exercise in falsification: "Propaganda by its very nature is an enterprise for perverting the significance of events and of insinuating false intentions" (1973, p. 58).

By contrast, the theorist qua theorist, pace Dr. Binad, is committed to understanding and explaining phenomena - in this case, propaganda. This entails that the theorist is dedicated to a family of truthvalues (truthfulness, accuracy, clarity, validity, objectivity, authenticity, realism, honesty) as he/she undertakes to explore and disclose the objects of an enquiry. ${ }^{4}$ By the same token, the theorist is committed to respecting the professional procedures and protocols which safeguard those values. Utility and application, while they are defensible both as motives and as part of larger context of concerns, are not the direct, immediate or supreme values in such an enquiry. The theorist's actions, unlike Ellul's characterization of the intrinsic falsification of the propagandist's enterprise, is immediately and directly motivated by the desire to explore, to disclose, to understand and to know - certainly not by a desire to engage in manipulation. Moran $(1979$, p. 186) remarks that "the stated and observed purposes" of genuine communication constitute one of the categories that distinguish it from propaganda (which he calls 'pseudocommunication'). ${ }^{5}$

Typically, statements of intent from the prefaces and introductory chapters of recent works on propaganda illustrate this deeper teleology at work. In the following selection of introductory statements from works on propaganda, what is most evident is the immediacy of this conventional theoretical commitment within a wider context of social concerns and instructional applications.

We also will argue that the historical context in which the original interest in propaganda as a phenomenon emerged has not been sufficiently analyzed. We hope to clarify this historical context....(Altheide \& Johnson, p. 2).

Our goal in launching Propaganda Review is to bring those kinds of manipulation out of the closet and to explore them under the rubric "propaganda." We want to develop the skeptical sneer elicited by isolated instances of propaganda into a deeper and more critical understanding. In short, we want to name propaganda as a political issue, to make it visible and recognizable so that it can be resisted (Darnovsky, 1987/88, p. 1).

The purpose of this book is to reintroduce the study of propaganda and to extend its development. To these ends, it arrays a number of contemporary theoretical perspectives, identifies and explores several key issues in propaganda analysis, and exemplifies the application of the two major research traditions (Smith, 1989, p. 2-3).

It is important, especially in a democracy, during an age characterized by ever more sophisticated uses of propaganda tech- 
niques, that Americans become informed about these devices, the psychological dynamics of what makes them effective, and how to counteract their effectiveness without withdrawing into abject cynicism. That's what this book is about (Pratkanis \& Aronson, 1992, p. xii).

Even when some of these authors reveal the practical aim of resisting the effectiveness of propaganda, this figures as something subsequent to their primary aim: analysis and understanding. At the same time as he distorts the epistemic imperatives of propaganda research and theorizing, Binad chooses to ignore these direction signals from his fellow theorists. Their testimonies might have alerted him to the fact that in the main his own brand of self-referential propaganda talk becomes progressively unrecognizable as a serious theoretical undertaking. Read unguardedly, the essay threatens to compound the confusion already surrounding our notion of propaganda.

There is also a deeper irony at work here. Dr. Uve Binad is a fiction. Perhaps a fictional spokesperson was chosen because this allows the writer to speculate more freely and excitingly about the nature and scope of propaganda. If our comments hit the mark, however, we can now conclude that some of the central motifs in Propaganda Talk appear to be just as tenuous as Binad's own status. Even though propaganda may still remain a tough construct to understand and define, at least we now have good reasons not to include Binad's membership claim as part of the definition.

\section{Endnotes}

1 According to Ellul (1980), modern technological society (of which propaganda is a major component) is a system of power relationships in which efficiency (la technique) and an overwhelming preoccupation with means work to erode values. The ethics of non-power (which does not mean impotence) denotes a sustained policy of limiting power in order to affirm human control over life. The examples he offers (p. 245) are reduced involvement in competitive practices (eg. auto-racing) and aggressive social behaviors linked to technological artifacts.

2 Using paradox, Ellul argues that propaganda is systemically amoral, but that it creates its own version of morality which is little more than a system of expediency. "Thus, in itself, propaganda doesn't follow an ethics, but it is obliged to use one and to build one." (p. 160) Because propaganda is antithetical to traditional moral values, it is essentially "antimoral." (p, 171) This and other articles by Ellul (e.g., 1980) clearly exemplify his chosen vantage point, outside the universe of propaganda, as a critical theorist of the system itself. This is why Binad's claim that "Ellul...knows he's a scoundrel" (p. 89) appears groundless.
3 In the climate of postmodern criticism, truth loses not only primacy, but much of its lustre. Literary critic George Steiner (1975, pp. 110 235) argues that the power to falsify is "crucial both to human liberty and to the genius of language" (p. 223). More recently, Nyberg (1993) suggests that falsity is rooted in our nature, and that, to a degree, it is a good. Accounts of mass media deception are legion, but it goes further than this. For over two decades there has been a noticeable erosion of the standard of truth in media criticism itself (Cunningham, 1986; McConnell, 1990).

4 To some this may seem to be a very benign, even inflexible conception of the theorist's commitments. Alternatives are conceivable. For instance, with Lorraine Code (1987), one might prefer to argue less literally that the theorist has rather both an epistemic and moral commitment to "knowing well", and that this, in turn, is enough to distinguish the theorist from the propagandist. "A kind of normative realism constitutes the implicit ideal of good knowing at the core of correspondence and coherence theories of truth and knowledge, too. Although actual correspondence relations are difficult, if not impossible, to establish, sustaining the effort to do so as well as possible is a mark of virtuous intellectual conduct." (p. 131) 
5 Qualitative differences between the intentionalities of the theorist and the propagandist, as well as between their resultant messages, are also reflected in J. A. Blair's (1988) instructive distinctions between acceptable and unacceptable forms of bias.

\section{References}

Altheide, David L. \& Johnson, John M. 1980. Bureaucratic Propaganda. Boston: Allyn \& Bacon.

Blair, J. Anthony. 1988. "What is bias?" In Selected Issues in Logic and Communication. Ed. Trudy Govier. Belmont, CA: Wadsworth.

Bogart, Leo. 1976. Premises for Propaganda: The USIA's Operating Assumptions in the Cold War. New York: Free Press.

Christians, Clifford C. \& Real, Michael R. 1979. "Jacques Ellul's contributions to critical media theory." Journal of Communication, vol. 29, pp. 83-93.

Code, Lorraine. 1987. Epistemic Responsibility. Hanover, London: University Press of New England.

Cunningham, Stanley B. "Terminal distortion: basal incoherence in some recent mass media criticism." Canadian Journal of Communication, vol. 12, no. 2, pp. 51-70.

Darnovsky, Marcy, Claude Steiner, Charles Rappleye, \& Frederic Stout. 1989. "What is propaganda, anyway?" Propaganda Review, vol. 5 (Summer), pp 6-13.

Doob, Leonard W. 1989. "Propaganda." In International Encyclopedia of Communications, vol. 3, pp. 374-378. Ed. E. Barnouw et al., New York: Oxford.

Eaman, Ross A. 1987. The Media Society: Basic Issues and Controversies. Toronto: Butterworths.

Ellul, Jacques. 1957. "Information and propaganda". Diogenes, vol. 18, pp. 61-77.

Ellul, Jacques. 1973 [1965]. Propaganda: The Formation of Men's Attitudes. New York: Random House.
Ellul, Jacques. 1980. "The power of technique and the ethics of non-power." In The Myths of Information: Technology and Postindustrial Culture, ed. Kathleen Woodward. Madison, WI: Coda Press Inc. Pp. 242-247.

Ellul, Jacques, 1981. "The ethics of propaganda: propaganda, innocence, and amorality." Communication, vol, 6, pp. 159-175.

Johannesen, Richard L. 1990. Ethics in Human Communication. Prospect Heights, IL: Waveland.

Jowett, Garth S. 1987. "Propaganda and communication: The reemergence of a research tradition." Journal of Communication, vol. 37. pp. 97-114.

Jowett, Garth S., \& O'Donnell, Victoria. 1992. Propaganda and Persuasion. Second ed. Beverly Hilss, CA: Sage.

Lemer, Daniel. 1980. "Revolutionary elites and world symbolism." In Propaganda and Communication in World History, ed. Harold Lasswell, Daniel Lerner \& Hans Speier. Vol. 2, pp. 371-394. Honolulu: University Press of Hawaii.

McConnell, Robert R. 1990. "Disappearance of the truth and realism in television criticism." Journal of Mass Media Ethics, 5, 191-202.

Moran, Terence P. "Propaganda as pseudocommunication." Et Cetera, 2, 181-197.

Nyberg, David. 1993. The Varnished Truth: Truth Telling and Deceiving in Ordinary Life. Chicago: University of Chicago.

Pratkanis, Anthony R. \& Aronson, Elliot. 1992. Age of Propaganda: The Everyday Use and Abuse of Persuasion. New York: W. H. Freeman. 
Rohatyn, Dennis. 1988. "Propaganda talk." In Selected Issues in Logic and Communication. Ed. Trudy Govier. Belmont, CA: Wadsworth. Pp. 73-92.

Selucky, Katka. 1982. Propaganda and Ideology. Montreal, P.Q.: McGill University (Working Papers in Communications.)

Silverstein, Brett. 1987. "Toward a science of propaganda." Political Psychology, vol. 8, no. 1 , pp. 49-59.

Smith, Ted D. (ed.) 1989. Propaganda: A Pluralistic Perspective. New York: Praeger.

Sproule, J. M. 1989. "Social responses to twentieth-century propaganda." In Ted D. Smith, ed., 1989, pp. 5-22.
Steiner, George. 1975. After Babel: Aspects of Language and Translation. New York, London: Oxford University Press.

Steinfatt, Thomas M. 1979. "Evaluating approaches to propaganda analysis." Et Cetera, vol. 36 , pp. 166-177.

STANLEY B. CUNNINGHAM DEPARTMENT OF COMMUNICATION STUDIES

UNIVERSITY OF WINDSOR WINDSOR, ONTARIO N9B $3 P 4$ 